\title{
Flora Tristán o acerca de una peregrinación emancipatoria norte-sur sur-norte
}

\section{Flora Tristán or about an emancipatory north-south-south- north pilgrimage}

\section{Flora Tristán ou cerca de uma emancipatória peregrinação norte-sul sul-norte}

Dra. Federica Scherbosky'

Recibido: 15/01/2017 - Aceptado: 03/03/2017

\begin{abstract}
Resumen:
El presente artículo tiene como objetivo pensar la vida y obra de Flora Tristán como una precursora del feminismo transnacional. En su vida y obra, cuestiones que por cierto hay que recalcar que no son inescindibles, se habilita una perspectiva dialógica entre mujeres, tanto de diferentes clases como así también de diversas naciones. Por su origen mixto, a saber, franco-peruana, es portadora de un cruce de mundos que le posibilita a principios del siglo XIX una visión crítica del colonialismo y la modernidad, pero más crítica aun en su análisis del capitalismo incipiente. En este entramado complejo y con una vida de explotación tanto en términos de clase como de género, es que Flora logra articular la demanda de reconocimiento de las mujeres, en términos jurídicos, sociales, políticos, económicos y sobre todo identitarios, para confluir luego en una demanda de reconocimiento de todos/as los/as oprimidos/as.
\end{abstract}

Palabras clave: Flora Tristán - feminismo - reconocimiento - emancipación

\section{Abstract:}

The present article aims to think about the life and work of Flora Tristán as a precursor of transnational feminism. In her life and work, not indescribable, a dialogical perspective is enabled among women from different

1 Argentina, Dra. en Filosofía. Instituto de Ciencias Humanas Sociales y Ambientales (INCIHUSA), perteneciente al Consejo Nacional de Investigaciones Científicas y Técnicas (CONICET) y Facultad de Educación de la UNCuyo. Contacto: fedescherbo@ yahoo.com.ar 
classes and different nations. Due to her mixed origin, namely French and Peruvian, she carries a crossroads of worlds allowing her, at the beginning of the Nineteenth Century, to have a critical view of colonialism and modernity, but even more critical in her analysis of incipient capitalism. In this complex framework and with a life of exploitation both in terms of class and gender, Flora is able to articulate the demand for recognition of Women, in legal, social, political and economic terms and, above all, in identity. A demand for recognizing all oppressed people.

Keywords: Flora Tristán - feminism - recognition - emancipation

\section{Resumo:}

O presente artigo tem como objetivo pensar a vida e obra de Flora Tristán como uma precursora do feminismo transnacional. Em sua vida e obra, questões que certamente devem ser enfatizadas, habilita-se uma perspectiva dialógica entre mulheres, tanto de diferentes classes, mas também de diversas nações. Por sua origem mista, ou seja, Franco-peruana, possui um cruzamento de mundos que lhe permitem no início do século XIX uma visão crítica do colonialismo e a modernidade, porém mais crítica em sua análise do capitalismo incipiente. Neste quadro complexo e com uma vida de exploração seja em termos de classe como também de gênero, é que Flora consegue articular a demanda de reconhecimento das mulheres em termos legais, sociais, políticos, econômicos e, especialmente de identidade, para logo confluir numa demanda de reconhecimento de todos / as os / oprimidos / as.

Palavras-chave: Flora Tristán - feminismo - reconhecimento - emancipação

"Y es sólo con palpables verdades, con hechos irrecusables, con lo que se puede esperar influir en la opinión pública. ¡Que las mujeres cuya vida ha sido atormentada por grandes infortunios hagan hablar sus dolores! Que expongan las desgracias sufridas como consecuencia de la posición que les ha deparado las leyes y los prejuicios que las encadenan; pero que hablen...".

(TRISTÁN 2006 78).

Flora padeció los tormentos de los que habla en el texto que encabeza este trabajo, y es desde ese padecimiento que sitúa su palabra. Se pone de pie sobre sus dolores y emprende el camino, aquella peregrinación que servirá de guía para otros discursos, para nuevas formas de vida. Nos cuenta su vida y sus vicisitudes para que podamos comprender 
desde dónde piensa, cómo se proyecta, y sobre cómo, a partir de una historia individual, puede lograrse una teoría de emancipación universal de todos/as los/as oprimidos/as. Aquella mujer fue siempre paria, ${ }^{2}$ jamás reconocida. De hecho, sus escritos no integran la mayoría de las historias de la literatura peruana ni latinoamericana. Tanto sus novelas como sus relatos de viajes y escritos autobiográficos siguen aún hoy desconocidos. Solo en Perú ha sido reconocida como precursora de la lucha por los derechos de la mujer mediante la creación, en 1979, de un centro llamado "Centro de la Mujer Peruana Flora Tristán", cuyo fin es combatir las causas estructurales que restringen la ciudadanía de las mujeres o afectan su ejercicio.

Breve pero intensa es la vida que nos relata Flora Tristán y Moscoso en Peregrinaciones de una Paria -uno de sus escritos más autobiográficos-. Allí logró condensar la mayor parte de su vida, como así también los quiebres fundamentales que la llevaron a emprender su lucha. Si bien había publicado dos breves textos previamente uno acerca de la acogida a las mujeres extranjeras y otro a favor del divorcio, es a partir de Peregrinaciones... que asumió completamente su escritura como modo de respuesta y responsabilidad ante el otro. Ese otro que primeramente fue la mujer en función de su situación singular, luego los/as esclavos/as ${ }^{3}$, con los que entra en contacto sobre todo en su viaje a Perú; posteriormente los/as obreros/as, particularmente en sus

2 Paria. (Del portugués. pária). Persona excluida de las ventajas de que gozan las demás, e incluso de su trato, por ser considerada inferior. Fuente: Real Academia Española en http: //buscon.rae.es/drael/SrvltConsulta? TIPO_BUS=3\&LEMA=Paria, $(17 / 12 / 16)$.

3 Resulta central analizar la vivencia de la esclavitud que Flora experimenta en el Perú, ya que esta situación es inescindible del tema racial. Como es sabido, los esclavos eran en su mayoría negros. Recién en diciembre de 1854 el presidente Ramón Castilla declara la libertad para los esclavos negros, casi a condición de que lucharan para él en la guerra civil que libraba contra José Rufino Echenique. Logra con esto que entre dos y tres mil negros peleen en su frente por lo que gana una batalla en enero de 1855, a menos de un mes de lograda su libertad. A pesar de estos avances, al tiempo los antiguos amos logran hacer volver a los antes esclavos a las haciendas para que siguieran trabajando a cambio de un magro salario y tiempo después logran que los indemnicen por la pérdida de mano de obra de sus haciendas. Por lo visto la libertad es un camino largo que implicará diversas luchas y reflexiones. 
experiencias londinenses, y a partir de allí la humanidad toda, al erigir un proyecto emancipador que considera no puede ser fragmentario. Su autobiografía constituye un entramado complejo que excede el modelo meramente epistemológico -en tanto reproducción de una vida-, como así también el performativo -como acto de autocreación en el momento de la escritura-, para arribar a un modelo que podríamos denominar ético, como la disposición de respuesta y responsabilidad ante el otro. Consideramos que es sobre la base de este entramado que se presenta, sobre todo, como un modelo político emancipatorio que Flora plantea para todos/as los/as oprimidos/as pero desde la perspectiva singular de la mujer, de aquella paria que nunca encontró no solo un lugar de cobijo y una buena posición social, sino primeramente un lugar de articulación genuina de su demanda. Esta no lograba ser articulada por el simple y tremendo hecho de que la mujer no tenía la posibilidad de la palabra. Su voz no era escuchada, su opinión no tenía cabida, ya que no se consideraba posible, mucho menos importante. La palabra como derecho que hoy podemos considerar básico e irrenunciable fue cercenada a las mujeres hasta no hace tanto tiempo y en muchas situaciones lo sigue siendo. En este sentido revalorizamos el proyecto de Flora Tristán, pues frente a la no existencia de esa valoración, a la no posibilidad de palabra, se dispone a la creación de un espacio posible, lo entrama, lo forja y lo proyecta. Ahí radica la importancia de su historia, en tiempos donde la mujer solo se pensaba, en el mejor de los casos, como un sujeto pasivo, portadora de los azahares del destino o de lo que los varones con benevolencia quisieran otorgarle. Flora transforma su vida en un proceso de construcción personal, con una dignidad irrenunciable que pretende se haga extensiva no solo a las mujeres sino a todo el género humano y lucha por eso.

Imposible le resulta pensar que su padecimiento es el único, que el cercenamiento de sus derechos es una situación particular y que por ende su lucha sería para la ampliación de sus derechos individuales. Vive en Francia la situación de las mujeres a las cuales se las sigue relegando en términos de derechos y espacios de decisión, analiza incluso la situación de las mujeres migrantes, relegadas doblemente, pues permanecen por fuera de cualquier derecho de ciudadanía, a 
las cuales como ya mencionamos les dedica un escrito con el objetivo de bregar por sus derechos. Vive en carne propia la prohibición del divorcio y en términos judiciales la anulación de su palabra, ya que no solo no existía el divorcio, sino que la mujer no tenía una palabra válida en términos judiciales. No podía ejercer el derecho de legítima defensa, ni la posibilidad de cualquier alegato. Su palabra una vez más allí estaba vedada. Pero mirando en derredor encuentra miles de mujeres en la misma situación y aun en algunas más graves. En su viaje a Perú, entra en contacto no solo con la denigración de las mujeres sino con la esclavitud. Hecho que asume y le genera diversas contradicciones hasta que logra ubicarlos/as como oprimidos/as y, por ende, como urgidos/as también de una emancipación. En este sentido se nos vuelven centrales las palabras de Levinas, quien afirma que se trata incluso de una obligación hacia el otro, como la imposibilidad de mantenernos indiferentes ante las desgracias y las caídas del vecino. (Levinas 1989 153). Nos interesa resaltar el proceso que realiza Flora Tristán a lo largo de su vida y cómo va asumiendo la condición de oprimido/a no sólo en su propia persona sino en la alteridad cotidiana que la obliga a actuar, que le imposibilita, como bien dice Levinas, permanecer indiferente. Va ampliando su horizonte de lucha y eso es lo que le imprime fuerza a su proyecto. Proyecto de emancipación para la humanidad oprimida toda.

Este acto fundamentalmente ético, político y emancipatorio se convirtió en un decir que antecedió e instituyó la posibilidad de todo intercambio lingüístico, de toda conversación y de toda temática. Decir como poder decir y como apertura del espacio para instalar su palabra. Y he allí el acto inaugural que implicó su escritura. A partir de su vida, de su voz, abrió el camino hacia el reconocimiento y la liberación de todos/as los/as oprimidos/as. Consideramos en este sentido que la noción de alteridad levinasiana se ajusta a su perspectiva de aquellos a los que considera como otros. El otro que sitúa primeramente como la viuda, el pobre y el huérfano, se encuentra en situación de desventaja, se encuentra necesitado de una respuesta que implique la responsabilidad para con él. Pero una responsabilidad que entiende como capacidad de responder, de actuar por el otro. Acción que resulta imposible deponer porque el rostro del otro demanda acción, 
demanda respuesta. $Y$ nos resulta especialmente importante resaltar aquí que Levinas señala que se trata del rostro. No de la mirada, no del llamado, no de la palabra, sino del rostro. Cuando no hay espacio a la palabra el rostro del otro conmueve, demanda un movimiento con y por el otro. Esta es la instancia en que consideramos se encuentra Flora en su registro de la alteridad, urgida a dar una respuesta ante ese rostro del/a oprimido/a que demanda.

Esa respuesta, devenida en un proyecto emancipador no podría entenderse sin tener en cuenta su historia personal. La vida de Flora Tristán comienza en París el 7 de abril de 1803, en plena época napoleónica. Fue hija de Mariano Tristán y Moscoso, coronel peruano oriundo de Arequipa, mayorazgo de una antigua y rica familia virreinal. Su madre fue Teresa Laisney, francesa educada en las ideas republicanas. Él estaba adscrito al ejército español y ella era parte de la emigración francesa, debido a las revueltas continuas en la Francia revolucionaria de la época. Se habrían casado en Bilbao, España en 1802, pero de modo clandestino, ya que él debía solicitar para ello permiso al Ejército, el que sin duda le sería negado por el enfrentamiento entre Francia y España de aquellos años. Realizaron así una ceremonia religiosa con un sacerdote francés, pero resultó nula para los requisitos de la época. Durante los primeros años de su vida, Flora no se vio privada de nada y creció en un hogar siempre concurrido por visitas del nivel de Simón Bolívar y su maestro Simón Rodríguez, cuestiones que anticipan y enmarcan su ideario emancipatorio y su impronta latinoamericana. Es de hecho Simón Rodríguez quien da aviso de la existencia de Flora a la familia de su padre en Perú. Instancia a la que ella apela para intentar probar su legitimidad, pero que como veremos más adelante no resulta como esperaba (Guardia 2016 89).

La muerte de su padre sumió a la familia en la pobreza. Sucedió repentinamente cuando Flora tenía cuatro años, sin que se hubiera regularizado el matrimonio ni las disposiciones testamentarias. El Estado revolucionario francés no reconoció a la viuda ni a los hijos, negándoles cualquier bien o derecho, por lo que Flora, su hermano y su madre disponiendo de escasos recursos para vivir se mudaron a las afueras de París, viviendo en barrios pobres, rodeados de mendigos, 
prostitutas y migrantes. Allí permanecieron hasta que ella alcanzó la edad de 15 años.

Mientras tanto en Francia las insurgencias revolucionarias habían sido apaciguadas por algo más de una década de Imperio Napoleónico, que aun finalizando en 1815, dejó importantes consecuencias, entre ellas el Código Napoleónico introducido en todos los nuevos Estados creados bajo el Imperio Francés. Se abolió el feudalismo y la servidumbre y se estableció la libertad de culto, a excepción de España. Le fue otorgada a cada Estado una Constitución en la que se concedía el sufragio universal masculino, una declaración de derechos y la creación de un parlamento. Fue instaurado el sistema administrativo y judicial francés, las escuelas quedaron supeditadas a una administración centralizada y se amplió el sistema educativo libre de manera que cualquier ciudadano pudiera acceder a la enseñanza secundaria sin que se tuviera en cuenta su clase social o religión. Aunque la creación de gobiernos constitucionales siguió siendo sólo una promesa, se suele pensar esta época signada por el progreso y la eficacia. No obstante en lo que respecta a los derechos de las mujeres y a políticas descolonizadoras el Imperio Francés no avanzó en absoluto. Hubo en la época denuncias acerca del androcentrismo en la declaración de los "Derechos del Hombre y del Ciudadano" de 1791, que más bien eran derechos del varón. Ya Mary Wollstonecraft publica en 1792 una Vindicación de los derechos de la Mujer, entre otros escritos emblemáticos en los que busca poner en pie de igualdad a las mujeres y salir del argumento del "sexo débil". En lo que respecta a la política de colonización si bien la figura de Napoleón fue clave para el proceso independentista latinoamericano, el avance en lo que respecta a políticas concretas no fue tal, ya que este restauró nuevamente en 1796 la esclavitud en las colonias francesas, que había sido abolida desde 1794.

En 1840 Flora publica Paseos en Londres, libro en el que vislumbraba con anticipación la amenaza que representó para Francia el bonapartismo. Sostuvo que Napoleón era un "antagonista de la libertad", un tirano y un déspota. Estuardo Núñez en un estudio introductorio que realiza en el libro mencionado relata que la sensibilidad social de Flora: 
[...] no se dejaba engañar por el espejismo de los grandes triunfos guerreros cuyo alto costo contrastaban con la miseria y los tremendos sufrimientos de los pobres. Lo había sostenido así en su ensayo "Lettres de Bolivar" (publicado en Le Voleur de Paris, 31 de julio de 1838) en que trata de descartar cualquier influencia bonapartista en el Libertador. Insiste en su tesis al tratar de los partidarios de tal tendencia refugiados en Londres. De Napoleón no queda -dirá Flora- sino "las huellas profundas de la opresión". Al dar a conocer sus opiniones, prevé con desazón, con diez años de anticipación, la posibilidad del advenimiento del príncipe Luis Napoleón, que entonces disfrutaba regiamente en su retiro de Londres, en espera del momento político favorable (Tristán 2001 8).

La promulgación de nuevas leyes y derechos, el de acceso al voto masculino y a la educación por parte de la burguesía -lo que les permitía erigirse políticamente en la sociedad-, junto con los principios fundamentales de libertad política, fraternidad e igualdad, constituyen el contexto donde Flora decide plasmar su lucha. Dicho contexto puso en evidencia lo importante del movimiento ilustrado. Sin embargo, se trataba de una racionalidad que quedaba fuera del alcance de las mujeres y sin duda también de los/as colonizados/as, por lo que Flora, en rechazo a una sociedad dividida construye un proyecto emancipatorio en el que confluyen lo que contemporáneamente podríamos denominar las problemáticas de género, raza y clase. Allí radica lo central de su perspectiva, en la capacidad de ver por detrás de lo aparentemente visible. No se engaña con los grandes triunfos guerreros y analiza el costo de esas guerras. Pretende desentrañar qué hay más allá del aparente discurso de progreso, de la eficacia, de la promulgación de leyes. ¿A quiénes abarcan esas leyes? ¿En qué o quiénes se sostiene ese progreso? ¿Quiénes acceden efectivamente a la educación y a los derechos? Serían algunas de las preguntas que suponemos como base de la mirada que va construyendo la paria. En esta misma línea de análisis, se entrelaza, la realidad y su anverso, como un ejercicio ético, político, epistemológico y emancipatorio. Por ello sostenemos que su propuesta puede pensarse desde el entramado 
"modernidad-colonialidad" que se sostiene desde la perspectiva decolonial. ${ }^{4}$ El foco de análisis no puede restringirse a pensar la modernidad como cualquier proceso histórico desvinculado en este caso de la colonialidad. Son parte de la misma moneda, o el costo necesario, diría Flora. Y justamente por eso consideramos centrales sus relatos de viaje a Perú y a Londres, pues expresan las vivencias particulares de la autora con una aguda indagación sobre el proceso histórico.

Cuando regresó a los dieciséis años a París sola con su madre, pues su hermano ya había muerto, debido a su mala situación económica comenzó a trabajar como obrera en un taller de litografía. Dos años más tarde, su madre la obligó a casarse con el propietario de ésta, André Chazal, con quien tuvo tres hijos, de los cuales sobrevivieron dos, una de ellos, la pequeña Aline, quien fue la madre del pintor Paul Gaugin.

Aquí comenzó una de las etapas más trágicas de la vida de Flora. Llegó a afirmar que a esa unión se debieron todos sus males. De hecho con solo veintidós años y con su hija Aline recién nacida decide abandonar su hogar para separarse de aquel hombre a quien no podía amar ni estimar. Así emprendió su segundo periodo de paria. Su padre había muerto sin legalizar la situación, y ahora tampoco tenía esposo. Pero incluso peor, ella lo había dejado. No era ni soltera ni viuda, pero tampoco divorciada puesto que habían prohibido el divorcio años atrás. Debe entonces ocultar su identidad y condenada a vivir como fugitiva, ya que si alguien la descubría las autoridades podían apresarla por contravenir el acuerdo matrimonial. Se inicia a partir de ese momento un desdoblamiento de su identidad, pues en sus viajes, tanto a Londres como a Perú se hace pasar por mujer soltera

\footnotetext{
4 La llamada teoría de la colonialidad o de la conolonialidad/descolonialidad ha sido desarrollada por Aníbal Quijano, Enrique Dussel, Walter Mignolo, Santiago CastroGómez, Nelson Maldonado Torres, Fernando Coronil, Edgardo Lander y otros. Ver, por ejemplo los libros colectivos: Lander, Edgardo (comp.). La colonialidad del saber: eurocentrismo y ciencias sociales. Perspectivas latinoamericanas. Buenos Aires: FLACSO, 2000, y también Castro-Gómez, Santiago y Grosfoguel, Ramón (eds.). El giro decolonial. Reflexiones para una diversidad epistémica más allá del capitalismo global. Bogotá: Pontificia Universidad Javeriana/Siglo del Hombre Editores, 2007.
} 
y sin hijos, situación por la que no deja de cuestionarse nunca y que vive en muchas instancias de manera conflictiva. Todo esto porque las vías legales existentes juzgaban con severidad la separación de los cónyuges y aún con mayor rigurosidad si la decisión era tomada por parte de la mujer.

Se hace patente una vez más cómo la situación de paria está enmarcada en el desamparo ejercido por la figura masculina. Flora es doblemente paria porque, primeramente, no tiene el resguardo paterno, un reconocimiento como hija legítima, que aun en ausencia de su padre la cobije, cuestión que busca en su viaje a Perú. Pero debido a su matrimonio frustrado con Chazal, la legitimidad que habría logrado conseguir en su adultez, el ser "señora de" y un respaldo que se suponía tanto económico como afectivo, queda una vez más relegado en función de un proyecto emancipatorio que en sus comienzos no ve tan claramente. Hay al inicio de la peregrinación de Flora, una búsqueda de legitimidad, de reconocimiento para salir de su situación de paria, hasta que logra empoderarse y recrearse desde ese lugar. Se trata de un proceso que le permite dejar de buscar la legitimidad en la figura masculina que ya no la cobija -y que podríamos suponer no la cobijó nunca, y erigirse a sí misma como sujeto autónomo y emancipado, como portadora de una voz valiosa de por sí, más allá de lo que los mandatos sociales impongan. Un espacio de palabra por construir y por el cual justamente lucha. Así relata su situación:

Supe durante esos seis años de aislamiento todo lo que está condenada a sufrir la mujer que se separa de su marido en medio de una sociedad que, por la más absurda de las contradicciones, ha conservado viejos prejuicios contra las mujeres colocadas en esta posición, después de haber abolido el divorcio y hecho casi imposible la separación de cuerpos. La incompatibilidad y mil otros motivos que la ley no admite hacen necesaria la separación de los esposos; pero la perversidad, sin suponer en la mujer motivos que ella pueda declarar, la persigue con sus infames calumnias. Excepto un número pequeño de amigos, nadie cree en lo que dice y, excluida de todo por la malevolencia, no es, en 
esta sociedad que se enorgullece de su civilización, sino una desgraciada paria a quien se cree demostrar favor cuando no se la injuria (Tristán 2006 84).

"De esa experiencia surgió su odio al sexo y al matrimonio, que consideró una institución intolerable, en la que la mujer es vendida a un hombre que la convierte en su esclava y sirvienta", apostilla Vargas Llosa (2003). Ya no es esta una institución en la que espere ser reconocida; de hecho, escribe a favor del divorcio influenciada por las ideas de Owen. Esta petición por el restablecimiento del divorcio la dirige a la Cámara de Diputados en 1837, instancia en la que una vez más podemos observarla como una adelantada a su época. Decepcionada del matrimonio, comenzó a trabajar como criada de una familia inglesa, por lo que debió viajar a Inglaterra. Fue en 1926, durante el primero de los viajes que realizó a ese país, cuando tomó contacto con el fervor industrial que por esos años se iniciaba. El descubrimiento de la máquina a vapor, la industrialización de la producción, el reemplazo del trabajo manual, las interminables e indignas jornadas laborales y la correspondiente precarización o mera reproducción de la vida de los/as proletarios/as, fueron cuestiones que Flora elaboró con el pasar de los años, hasta arribar al socialismo y su consecuente lucha.

Su experiencia inglesa -comenzada a los 23 años- llena los mejores años de su vida y culmina a los 37 años cuando en plena madurez, publica finalmente el libro Paseos en Londres. Así como Peregrinaciones de una paria no se trata solo de un relato de su viaje a Perú, sino que puede leerse como un proyecto emancipador en diferentes claves, del mismo modo su libro sobre Londres es más que un simple relato de viaje. Se trata de un testimonio crítico, una suerte de reportaje-informe sobre las condiciones sociales prevalecientes en ese país europeo. Como bien afirma Estuardo Núñez, "el libro de Flora Tristán constituye -desde su mirador social de lucha y denuncia- el primer estudio social de la realidad europea intentado por un escritor latinoamericano" (Tristán 2001 7). Señala este mismo autor que el modo de relato de Flora sobre la realidad europea, particularmente la londinense, se aleja de dos autores peruanos que ensayaron también sus relatos de acontecimientos alrededor de 1850 y 1860, a 
saber Juan Bustamante y Juan de Arona. Pero que curiosamente se acerca -adelantándose una vez más a su tiempo- a otros testimonios peruanos sobre Europa en el siglo XX, como los de Francisco García Calderón y José Carlos Mariátegui, quien enfocó el fenómeno social europeo desde una perspectiva de clara posición ideológica de izquierda. Señala entonces que:

El libro de Flora Tristán fue el resultado de sus experiencias vividas en la Inglaterra de su época, en diversas fechas: en 1826, cuando la aprecia próspera sin importarle los problemas internos; en 1831, cuando empieza a ser poseída por la inquietud social; en 1834, cuando ya capta el descontento de la clase media y también la presión de la clase obrera; en 1839, cuando en Londres, encuentra una miseria profunda y lacerante en el pueblo y "el surgir de una extrema irritación y el descontento general". Este espectáculo la decide a escribir para ofrecer al público un libro que no tiene la pretensión "de pintar todas las miserias del pueblo inglés" sino sólo la de bosquejar las pocas cosas que ha visto en ese país y hacer conocer las impresiones que obtuvo. Era un libro franco, sin tapujos y lleno de indignación y de protesta, con el cual esperaba llamar la atención de aquellos que "quieran realmente servir la causa del pueblo inglés" (Tristán 2001 6).

De regreso a Francia, en 1829, una casualidad tuerce el rumbo de sus días. En un bar, un marinero le dio noticias de una familia con ese nombre que vivía de forma opulenta en Arequipa, Perú. Era la familia del hermano menor de su padre. Flora le escribió y en 1833 decidió viajar a Perú para reclamar la herencia de su padre que le correspondía. Sus palabras muestran la sinceridad de su anhelo, no sólo económico, sino social y afectivo. La necesidad de sentir algún tipo de pertenencia, un amparo que resguarde a esta mujer sola en el mundo. "He nacido en Francia, pero soy del país de mi padre... Viajo con la esperanza de encontrar en el Perú una posición digna que me haga entrar de nuevo en la sociedad y de refugiarme en el seno de mi familia paterna" (Tristán 2006 199). 
La travesía de su viaje a Perú y el cambio que esto implicó en su vida es lo que la impulsó a escribir Peregrinaciones de una paria, que publicó en 1838. Recoge vivencias de su viaje que traducen una imagen peruana muy personal, ácida y penetrante, dirigida a los europeos para advertirlos y a los propios connacionales para sacudirlos del conformismo, de la apatía y de las costumbres retrógradas e hipócritas. Da cuenta allí del contraste de culturas entre el "clásico y civilizado" mundo europeo, y la vida peruana. En principio, se trata de un viaje esperanzador al Nuevo Mundo, aunque en él no encuentra asidero la leyenda dorada ni cobijo su demanda.

Muestra la terrible situación en la que también vivían las mujeres del "Nuevo Mundo", con costumbres aún más retrógradas que las europeas, sumándole a su vez la presión de una religión vacía que ella consideraba como superstición. No obstante, Flora se presentaba como una mujer creyente y de fe que acudió a Dios en todo momento y que aceptó de la voluntad divina su destino, ya que debía, sin duda, hacerla libre. Distinguía claramente el actuar por imposición social de lo que a materia de fe correspondía. Era Dios quien le había dado su fuerza moral, la voluntad que la empujaba siempre hacia delante y posibilitaba todo su camino de reivindicaciones y de lucha. Sostenía que el móvil, tanto de ella como de los otros hombres heroicos, era la fuerza del amor infundida por Dios. De hecho, cuando piensa en su situación de paria la define en función de un mandato divino, en sus palabras: "uno de esos seres elegidos, a quienes Dios ha dotado de un coraje a toda prueba, preparado para sufrir martirio y soportar la esclavitud si fuera necesario" (Id. 85). Culminó en una especie de mística amorosa que la llevó a una profunda misericordia hacia la humanidad. "La raza humana sufre y no es despreciable. La compadezco por la desgracia que se ha causado a sí misma y la amo porque es desgraciada" (Id. 120).

Desgracias de las que tomó conciencia plena en su estadía en el Perú, no solo por la guerra civil, los conflictos de poder y religión, y por la indigna existencia a que son sometidas las mujeres, sino además por la gran diferencia entre las distintas clases sociales, el menosprecio a los nativos y la trata de negros. Flora confesó que en un principio sus 
pensamientos y creencias eran muy ingenuas, y que aun habiendo sufrido ya mucho, no era consciente de la maldad humana, de sus vicios e iniquidades. Solo abriéndose a la vida, al mundo, viajando adquiere nociones reales de la atrocidad en la que la humanidad se encontraba. En este sentido podemos señalar un proceso en su comprensión del sistema colonial, ya que si bien en un primer momento adhiere a las clásicas nociones coloniales de Viejo y Nuevo Mundo, de lo nativo como lo retrógrado y lo europeo como la alta cultura, con el transcurso de su estadía en Perú logra conceptualizar el entramado del sistema colonial. Allí se descubre e identifica con las mujeres peruanas oprimidas por el patriarcado, al mismo tiempo que observa las diferencias históricas, culturales y religiosas. Señala entonces que más allá de la multiplicidad de modos de vida, las mujeres deberían aunarse en un proceso conjunto de lucha por su emancipación, sin dejar de contemplar y dar cuenta de las particularidades que no logran subsumirse. Si bien no lo analiza con el entramado categorial del sistema "modernidad-colonialidad", que consideramos no termina de visualizar claramente, logra una vinculación entre clase y género, propia de los círculos de los socialistas franceses que consideran que fruto de la igualdad de clase devendrá la igualdad de género, o al menos mayores derechos para la mujer.

Sin embargo, a modo de respuesta, Flora denuncia lúcidamente que los derechos de las mujeres no pueden subsumirse a los de clase, porque implican luchas a la vez diferenciadas y conjuntas. Consideramos en este sentido que es precursora de un feminismo amplio, que logra encausar diferentes luchas sociales pero sin priorizar ninguna de ellas por sobre las otras, aunque siempre se sostenga desde su perspectiva de mujer militante.

En sus estadías en Londres, años más tarde se horrorizó aún más de las condiciones de vida del proletariado, y afirmaba que "la esclavitud no es a mis ojos el más grande de los infortunios humanos desde que conozco al proletariado inglés" (Tristán 2001 56). A partir de aquí y con los posteriores viajes a Inglaterra elaboró su doctrina socialista en apoyo a los/as proletarios/as, los/as esclavos/as, las mujeres y oprimidos/as en general. Su camino era la búsqueda incesante de libertad, pero no de sí 
misma sino de toda la humanidad, no ya por sectores, clases o países, como lo muestra en un testimonio que nos dejó en Peregrinaciones..., donde exponía un tajante cambio de su pensamiento.

En 1833 me hallaba todavía muy lejos de tener ideas que después se han desarrollado en mi espíritu. En aquella época era muy exclusivista. Mi país ocupaba en mi pensamiento más sitio que todo el resto del mundo. Era con las opiniones y los usos de mi patria con lo que juzgaba las opiniones $y$ usos de los demás. El nombre de Francia y todo lo que se vinculaba con ella producían sobre mí efectos casi mágicos. Entonces consideraba a un inglés, un alemán o un italiano como a otros tantos extranjeros. No veía que todos los hombres son hermanos y que el mundo es su patria común. Estaba todavía muy lejos de reconocer la solidaridad de las naciones entre sí, de donde resulta que la humanidad íntegra experimenta el bien y el mal de cada una de ellas. Pero relato mis impresiones tal como las sentí a la vista de nuestra superioridad sobre los individuos de las otras naciones que se encontraban en la Praia5 (Tristán 2006 109).

Aquí es donde comienza a desarrollarse de modo cabal su noción de reconocimiento, ya que se produce un giro en su apuesta por la igualdad hacia la noción y vivencia de la diversidad. No solo franceses/ as o peruanos/as, mujeres o esclavos/as, si no que la trama se complejiza y entrecruza, lo que va generando apertura y profundidad en su pensamiento y consecuente acción.

El viaje que emprendió a Perú era en busca de la legitimidad y la herencia que, como ella pensaba, le correspondían. Si al salir buscaba su identidad y legitimación personal, volvió con ideas más claras acerca de los problemas y las injusticias que aquejan no sólo a la mujer, sino también la esclavitud, la marginalidad, el problema racial y la subalternidad en la que todos estos sujetos se encuentran. Perú

5 Praia es la capital de Cabo Verde, donde el navío recala unos días para algunos arreglos, antes de seguir su camino hacia Perú. 
implicó para ella una apertura indescriptible, una nueva y consolidada cosmovisión que fortaleció su entereza. "Flora Tristán regresó a París transformada en otra persona" (2003), sentencia Vargas Llosa. La mujer menuda que llevaba aguantando desgracia tras desgracia se había transformado en una resuelta agitadora. "Como habían hecho otros grandes utopistas de su época, se propone diseñar la sociedad perfecta desde el punto de vista de la mujer" (Ibid.), sostiene el literato. Tristán había comprendido en Perú que la mujer no solo podía, si no que debía ser liberada.

A su regreso a París frecuentó círculos intelectuales, comenzó sus estudios acerca de los sansimonianos y fourieristas, y enfatizó su preocupación por la situación de la mujer y de los/as obreros/as. Publicó en 1835 Sobre la necesidad de prestar una ayuda a las mujeres extranjeras. Comenzó poco a poco a ser reconocida y en 1837 escribió su segundo trabajo a favor del divorcio. Un año después publicó una de sus obras más reconocidas, Peregrinaciones de una paria, y a partir de allí continuó con una seguidilla de publicaciones. Escribió una novela, Mephis o El proletario, tradujo unas cartas de Bolívar, y en 1840 fruto de sus estadías en Inglaterra escribió Paseos en Londres. En 1843, La Unión Obrera, y dejó un escrito sobre La emancipación de la mujer, que se editó póstumamente.

Su reconocimiento en Francia le trajo aparejadas nuevas persecuciones de su marido, ya que este creía que había vuelto con dinero del Perú. Las controversias continuaron hasta que finalmente su esposo le disparó dos veces. Las balas que no la mataron, en realidad la liberaron, puesto que con esto logró que Chazal fuera a la cárcel. Flora pudo al fin dedicarse plenamente a su radical desafío político. Sin embargo, su salud quedó deteriorada, ya que una de las balas, no pudo ser extraída, por su cercanía al corazón, ocasionándole malestares que la acompañaron hasta el día de su muerte. Le quedaban aún unos cuantos años de actividad desenfrenada hasta que finalmente falleció a los 41 años, en Burdeos, en 1844, víctima de tifus.

Vargas Llosa en una de las entrevistas relacionadas con su libro El Paraíso en la otra esquina, declara: 
Lo admirable de Flora Tristán es que no encuentro en ella la cultura de la queja. No se lamenta. Actúa. Un principio que parece estar de acuerdo con su propia forma de ver la vida, donde nunca ha evitado tomar partido cuando lo han exigido las circunstancias (2003).

Su carácter de militante revolucionaria la hacía estar convencida de que las mujeres no podrían liberarse solas del yugo que las esclavizaba, quiso unir esta lucha con la de los/as obreros/as en L'Union Ouvrière. Con este objetivo emprendió una gran gira por Francia en 1844 y describió todos sus problemas, fracasos, persecuciones y dolores en su Diario (publicado en 1973).

Esta convicción es uno de los pilares del pensamiento de la paria, ya que no solo planteaba sino que unificaba e integraba los cuestionamientos tanto del feminismo como del socialismo. Solo pocas mujeres, como Mary Wollstonecraft y Olympe de Gouges habían podido hasta entonces instalar su voz y reclamar lo que les correspondía, aunque es debido señalar que Olympe muere en la guillotina, el libro de Wollstonecraft fue prohibido en el momento en que apareció y de la misma manera Peregrinaciones de una paria fue incinerado cuando llegó a Perú. Paseos en Londres no circuló en América, mucho menos en Perú, a pesar de las cuatro ediciones que se realizaron en esos años, cuestión que da cuenta del ambiente hostil en el que desenvolvía su lucha. Además, los planteos socialistas de la época no incluían a las mujeres, o de lo contrario postulaban que fruto de la igualdad social se llegaría a una igualdad de género. Mientras que adelantándose a su tiempo, señala Alexa Payán:

Flora Tristán comenzaba a darse cuenta de que el éxito del socialismo no conllevaría necesariamente la emancipación de las mujeres. En este punto se había plantado la primera semilla del pensamiento y la contribución de Flora: la liberación de las mujeres tenía que ser paralela al movimiento socialista; la igualdad absoluta de las mujeres daría como resultado una sociedad verdaderamente equitativa (Payán 2003 278). 
Aunque las ideas planteadas por Flora Tristán, tanto en el terreno de la lucha obrera como en el de las reivindicaciones feministas, no cobraron de inmediato derecho de ciudadanía, contribuyeron efectivamente a trazar el camino que habría de conducir, muchas décadas más adelante, a consolidar avances reales para ambos grupos sociales. De hecho, Karl Marx afirmó años más tarde que Flora Tristán era "una precursora de altos ideales nobles", y junto con Engels concluye en el estudio que realizan sobre el Socialismo Utópico en La Sagrada Familia, que "Flora Tristán es el ejemplo de ese dogmatismo femenino que pretende poseer una fórmula y se la crea tomándola de las categorías de lo existente" (Tristán 2001 11).

En relación a su vinculación con el socialismo Estuardo Núñez reafirma entonces que:

Flora Tristán es el primer viajero peruano con espíritu crítico. Nacida en Francia, hizo su vida en ese país, bregando por mejorar la suerte de los desheredados. Como mujer de lucha, se adelanta en sus formulaciones sociales a las ideas marxistas y prepara sin tregua, con una organización que fundó en Burdeos, la "Unión obrera", el advenimiento de la primera revolución de los proletarios, la de 1848 (Tristán 2001 6).

Europa no había recibido antes una admonición y censura semejantes por parte de un escritor latinoamericano. Si bien La Unión Obrera y Mephis, o El proletario son obras que impactan en las clases explotadas; el sentido crítico y de denuncia ética, política y social hacia Europa y su proyecto de capitalismo en expansión, se concentra sobre todo en Paseos en Londres. Si bien critica también allí la organización social francesa, se hace eco del rechazo francés contra las manifestaciones de la prepotencia del imperialismo británico gravitante sobre el resto de Europa y del mundo. De igual modo percibe las infiltraciones imperialistas en su viaje de más de un año por Chile y Perú, pues Inglaterra extendía entonces sus redes para invadir aquellas excolonias de España, cuyo comercio, minería y crédito empezaban a ser copados por agentes ingleses que conducían el sistema de dominio capitalista imperante desde las islas británicas a otros ámbitos extranjeros, desplazando al comercio francés. Cabe destacar que estas infiltraciones 
imperialistas fueron posibles debido a la constitución de una subjetividad minorizada que se conformó producto de la conquista y colonización. Subjetividad minorizada en sentido kantiano, que necesita de una ilustración, pero con una racionalidad no restringidamente europea, blanca, masculina y héteronormada.

Es este peregrinaje norte-sur, y también sur-norte -París-Londres-PerúLondres- el que le posibilita visualizar un proyecto moderno ambivalente, del cual resultan inherentes el florecimiento de Europa a costa de una conquista brutal, la exaltación de la industria inglesa a costa de su pueblo miserable. Flora ofreció una versión distinta del mundo europeo. Ya no la versión de la vida oficial, del acontecer banal, de las figuras cumbres o de lo pintoresco y anecdótico, sino el anverso de esa imagen: la vida del pueblo pobre, la esclavitud, las condiciones lamentables del trabajador, la explotación social, la prostitución, el inhumano trato de la mujer y el niño, la indiferencia de los poderosos frente a las condiciones de injusticia.

Todos sus escritos, pero sobre todo los dos que se ofrecen como relatos de viajes nada menos que a Perú y a Londres, sintetizan su ideario emancipador en una sociedad de poderosos/as y explotadores/as de un lado, y de humillados/as y explotados/as de otro. Se adelantó a su época con su planteamiento de la emancipación social aun entonces muy mediada por la persistente actitud idealista y débilmente reformista. Propugnó un igualitarismo radical en un momento en que se erigía aún con más fuerza la diferencia entre clases, entre aristocracia, burguesía y proletariado y cuando al/a desposeído/a solo se le concedía, en el mejor de los casos y paternalmente, derechos limitados. Su propuesta de una sociedad sin clases, sin explotados/as, que la ubica como una pensadora anticapitalista, es por lo cual Marx y Engels la colocan en la rúbrica de "socialistas utópicos". No obstante, nos interesa resaltar, como bien señala Estuardo Núñez, que "Quien había clamado en el Perú contra el régimen de la esclavitud que vio todavía vigente en la hacienda de Villa a pocos kilómetros al sur de Lima, podía también condenar la condición miserable de los tugurios londinenses y de las fábricas y minas inglesas en donde los trabajadores -hombres, mujeres y niños- laboraban en condiciones infrahumanas" (Tristán 
2001 9), instancia que da cuenta de una perspectiva más amplia de la opresión, en relación incluso al mismo Marx. El viaje a Perú es el que le posibilita tomar conciencia temprana de la esclavitud, vinculada siempre a la condición racial, hecho que en Marx no está presente. A la que se suma la persistente preocupación específica sobre la opresión patriarcal, eje central de la obra de la paria.

Se trata entonces de un proyecto emancipador que clama por la unidad de los/as desposeídos/as como único camino posible para hacer escuchar su voz y obtener el reconocimiento de sus derechos. Unos años antes que Marx realizara su llamamiento a la unidad de los proletarios, Flora hace lo suyo; pero no solo con los/as proletarios/as, sino también con las mujeres, los/as esclavos/as y cualquier explotado/a del mundo en busca de dignidad, libertad y reconocimiento. Consideramos que su obra es precursora de un entrecruzamiento de perspectivas para pensar y proponer los procesos emancipatorios tanto en términos de raza, como de clase y género. Se trata en definitiva de una lucha contra la opresión en general que no deja de complejizarse a partir de este peregrinaje norte-sur y sur-norte que la caracteriza y la conforma.

Flora Tristán hizo pública su dolorosa existencia privada. Así construyó una propuesta transgresora y libertaria, patentizando la complejidad y las múltiples simultaneidades de la transformación social. La suya fue una incansable peregrinación hacia una sociedad igualitaria, con una perspectiva centrada en las reivindicaciones de los derechos de la mujer pero que se encaminaba hacia la liberación de todos/as los/as oprimidos/as, hacia el reconocimiento y la vivencia de una humanidad plena. Inicia un peregrinar norte-sur que le habilita una perspectiva diferente de los procesos emancipatorios, de los "encuentros" entre culturas pero con una base material y de clase que no deja pasar; por ello sus contrariedades ante la esclavitud, que aun arrepintiéndose años más tarde no deja de asumir y relatar. Su tránsito norte-sur y sur-norte, como así también su habitar en un mundo proletario y frecuentar otro burgués, su desplazamiento por su condición de mujer, junto con la creación y habilitación de un espacio de vida y de palabra que normalmente era articulado por varones son las temáticas fundamentales que relata en este ejercicio autobiográfico, 
al que convierte en un espacio de lucha ética y política. La autobiografía como proceso de autoconstrucción y de autoreconocimiento posibilita darle la cabalidad del sentido a los lemas que sostienen que "lo personal es político", pues al hacer pública su existencia privada logra articular un proyecto emancipatorio para la humanidad oprimida en su conjunto.

\section{Bibliografía}

Castro-Gómez, Santiago y Grosfoguel, Ramón. (eds.). El giro decolonial. Reflexiones para una diversidad epistémica más allá del capitalismo global. Bogotá: Pontificia Universidad Javeriana/Siglo del Hombre Editores, 2007.

Cevasco, Gabriela. El Tour de Francia. Centro de la mujer peruana: Flora Tristán. Disponible en: http://www.flora.org.pe/index.htm (10/06/09)

Guardia, Sara Beatriz. Dominga, Francisca, Flora. Soy una fugitiva, una profana, una paria. Arequipa: Editorial UNAS, 2016.

Lander, Edgardo. (comp.). La colonialidad del saber: eurocentrismo y ciencias sociales. Perspectivas latinoamericanas. Buenos Aires: FLACSO, 2000.

Levinas, Emmanuel. Ethics and Infinity. Conversations with Philippe Nemo. Pittsburgh: Duquene University Press, 1985.

Levinas, Emmanuel. "God and Philosophy". En: The Levinas Reader, Hand, S. (ed.), Oxford: Basil Blackwell (1989). 166-189.

Loureiro, Ángel G. "Autobiografía: el rehén singular y la oreja invisible". En: The Ethics of Autobiography. Replacing the Subject in Modern Spain. Nashville: Vanderbilt University Press, 2000. Disponible en: http://rua.ua.es/dspace/ bitstream/10045/7338/1/ALE_14_06.pdf (26/10/09)

Miguel, Ana de y Romero, Rosalía. Flora Tristán: Feminismo y Socialismo. Antología, Madrid: Colección Clásicos del Pensamiento Crítico, Editorial La Catarata, 2003.

Payán, Alexa. Flora Tristán. Dueña del porvenir. México: Plaza y Janés, 2003.

Tristán, Flora. Peregrinaciones de una paria (1838). Lima: Centro de Producción Fondo Editorial Universidad Nacional Mayor de San Marcos, 2006.

Tristán, Flora. Paseos en Londres. (1840). Lima: Biblioteca Digital Andina, 2001. Recuperado en: http://www.comunidadandina.org/bda/docs/PE-OC-0007. pdf, $(10 / 12 / 16)$ 
Urién, Leticia. "Una subjetividad declinada en femenino: Flora Tristán". Nómadas. Revista Crítica de Ciencias Sociales y Jurídicas 11(1) (2005): 1-16.

Vargas Llosa, Mario. El Paraíso en la otra esquina. Buenos Aires: Alfaguara, 2003. Disponible en: http://biblioteca.vitanet.cl/colecciones/800/860/863/ paraisoenotraesquina.pdf (10/12/16)

Entrevistas a Vargas Llosa publicadas en: http://www.convencion.org.uy/ menu6-062.htm (10/6/09) y http://www.geocities.com/circulodelectura/ paraiso.html (10/6/09)

Wollstonecraft, Mary. Vindicación de los derechos de la mujer. Madrid: Ediciones Istmo, 2005. 